\title{
The Pioneers of Pediatric Medicine
}

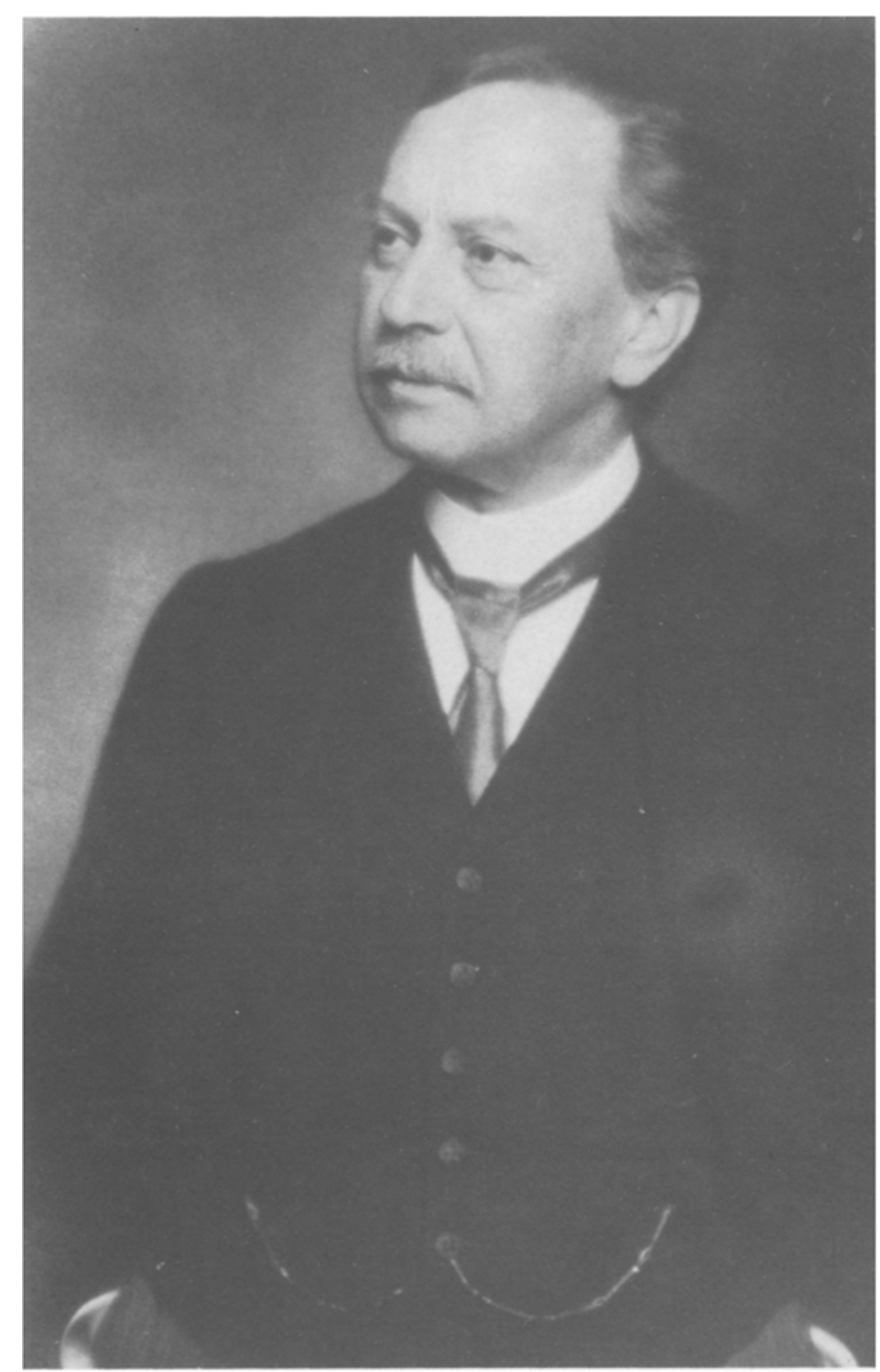

\section{Adalbert Czerny}

(1863-1941)

Director of the University Children's Hospital in Breslau from 1898 to 1910, in Straßburg from 1910 to 1913, Berlin (Charité) from 1913 to 1932 and, after his retirement, in Düsseldorf from 1934 to 1936.

He was a brilliant paediatrician who stimulated much interest in science in his time. In 1906, he coined the phrase on nutritional disease, "ex alimentatione, ex infectione, e constitutione". In 1906, he introduced the expression "toxicosis" and wrote on the subject of the nutritional deficiencies of milk and flour, as well as on alimentary anaemia. The handbook he co-authored with Arthur Keller on children's nutritional diseases was a standard work for a long time. From 1906 to 1908 , he worked on the concept of "exudative diathesis" (in the context of research for hereditary dispositions and "constitutional" diseases) and in 1909 suspected a "congenital defect in the body's reaction mechanism" to be the cause of this predisposition to disease. In 1918, he introduced Buttermehl nutrition together with H. Kleinschmidt. In 1908, his famous little book The Doctor as the Educator of the Child appeared. 